\title{
Da incerteza ao inconsciente: confluências entre ciência e psicanálise
}

*Artigo desenvolvido a partir de pesquisa realizada para a disciplina "Lógica e práticas discursivas jornalísticas", dirigida aos alunos de graduação do primeiro semestre do curso de jornalismo da Escola de Comunicação e Artes da USP.

Rosana de Lima Soares Escola de Comunicação e Artes/ECA-USP 


\section{Resumo}

Na primeira metade do século 20 , uma instigante confluência parece acontecer entre as descobertas científicas e o campo das chamadas ciências humanas. Dizemos confluência por entendermos que o surgimento de uma nova concepção de sujeito leva à modificação nas concepções da ciência clássica e, ao mesmo tempo, é por haver a possibilidade de questionar a assertividade e a objetividade da ciência que um novo conceito de sujeito pôde emergir. Ao estabelecer tais correlações, acreditamos poder demonstrar a radicalidade do pensamento freudiano, que ao articular o conceito de inconsciente traz à cena das ciências humanas a possibilidade de pensar, a exemplo do que acontecia nas ciências exatas, a incompletude e a imprevisibilidade, a incerteza e o caos; da mesma forma, apenas um sujeito desde sempre faltante poderia sustentar tais rupturas no campo da investigação científica.

\section{Palavras-chave}

sujeito, inconsciente, ciências humanas, incompletude, linguagem

\section{Abstract}

In the first half of the 20th century, an instigating confluence seems to happen between the scientific findings and the field of the so-called human sciences. We say confluence because we understand that the emergence of a new conception of subject leads to changes in the classic science's conceptions. At the same time, the possibility of questioning science's assertiveness and objectivity allowed the emergence of a new concept of subject. Upon establishing such correlations, we believe that we are able to demonstrate the radicalism of the Freudian thought, which, when articulating the unconscious concept, brings to the human science's scenery the possibility of thinking - as it happened in the exact sciences - the incompleteness and unpredictability, the uncertainty and chaos; likewise, only an ever lacking subject could sustain such breach in the field of scientific investigation.

\section{Key words}

subject, unconscious, incompleteness, human sciences, language 
"Tais idéias abstratas - que depois se tornarão os conceitos básicos da ciência - são ainda mais indispensáveis à medida que o material se torna mais elaborado. Devem, de início, possuir necessariamente certo grau de indefinição; não pode haver dúvida quanto a qualquer delimitação nítida de seu conteúdo. Enquanto permanecem nessa condição, chegamos a uma compreensão acerca de seu significado por meio de repetidas referências ao material de observação do qual parecem ter provindo, mas ao qual, de fato, foram impostas. Assim, rigorosamente falando, elas são da natureza das convenções - embora tudo dependa de não serem arbitrariamente escolhidas mas determinadas por terem relações significativas com o material empírico, relaçōes que parecemos sentir antes de podermos reconhecê-las e determiná-las claramente."

Sigmund Freud

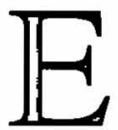

ste artigo busca mostrar a radicalidade do pensamento freudiano, que ao articular o conceito de inconsciente traz à cena das ciências humanas a possibilidade de pensar, a exemplo do que acontecia nas ciências exatas, a incompletude e a imprevisibilidade, a incerteza e o caos.

Partimos do pressuposto de que, ao pensarmos em teorias, não podemos negligenciar seu caráter de ficçãa $o^{1}$ : enquanto formas construídas por meio da linguagem, delas não se pode dizer que representem um mundo, tentando revelá-lo (nos moldes da ciência clássica), mas sim que apresentam o mundo, ao elaborar explicações sobre seus diversos aspectos (nos moldes da ciência contemporânea). Não que os acontecimentos não existam enquanto eventos que tiveram lugar. Mas só são vistos como realidade por meio de construções narrativas operadas pela linguagem; entre tais construções, temos as diversas teorias científicas, sejam elas no campo da

1. Lembramos aqui as noções de Feyerabend (2000), quando aponta para o caráter mitológico da ciência e da verdade; de Quéré (1982), ao tratar do fazer jornalístico como dotado de elementos de ciência e de ficção; e de Mannoni (1979) ao afirmar que, enquanto construção narrativa, a própria teoria caracteriza-se como ficção. 
física ou da filosofia. Nessa construção, pela própria estrutura descontínua da linguagem - que não poderá jamais tudo dizer -, algo sempre vai faltar - um pedaço não recoberto, não simbolizado.

O modelo das chamadas ciências exatas (como a física e a matemática), tem servido de inspiração para as ciências ditas humanas (como a sociologia e a psicologia) desde a antiguidade. Se tomarmos o positivismo filosófico, passando pelo behaviorismo na psicologia e pelo funcionalismo na sociologia, é toda uma tradição do pensamento que oscila entre os critérios de objetividade, neutralidade, causalidade, buscando estabelecer seus pressupostos em princípios que possam ser definidos como claros e evidentes. A exemplo do silogismo aristotélico, berço da lógica dedutiva que inspirou o modelo da pesquisa científica por centenas de anos, nas ciências humanas vemos uma constante tentativa de apreender ações e comportamentos em conjuntos bem estruturados, compactos e fechados nos quais as regularidades possam levar ao estabelecimento de padrões de normalidade e conduta.

Isso se estende a diversos campos do humano: a comunicação, com sua perspectiva linear representada no esquema clássico de transmissão e recepção de mensagens; a sociologia e a política, com seus cálculos estatísticos e formas de mensuração numérica; a filosofia, com seu eterno desdobrar-se sobre si mesma ao interrogar se o pensamento pode ser apreendido pelo próprio pensamento; a psicologia, com seus experimentos laboratoriais e regras visando à adaptação do indivíduo aos padrões sociais; a psiquiatria, em sua associação à biologia e à química, atribuindo às doenças psicossomáticas (depressão, medo, melancolia, dependência, fobia) suas respectivas drogas (dos quais o prozac se apresenta como um dos mais bem sucedidos remédios para os males da alma).

Mesmo em um simples exercício cotidiano, como a leitura de jornais, se observarmos a forma como as notícias diárias são estruturadas - especialmente aquelas relacionadas a atos inesperados (como o que ocorreu nos Estados Unidos em 11 de setembro de 2001), ou a comportamentos tidos como desviantes (como por exemplo o tema da descriminalização do uso de drogas) - o que vemos 
são tentativas constantes de se perpetuar experiências mensuráveis e padrões de controle, estabelecendo relações objetivas

Tal tentativa de apreensão objetiva é, na maior parte das vezes, tomada como se fosse uma forma ideal de se fazer ciência e, consequientemente, produzir conhecimentos seguros e verdadeiros. Entretanto, se observarmos o desenvolvimento de diversas concepções científicas ao longo do século 20 , em conjunção com as reflexões ensejadas pela filosofia da ciência, veremos que, neste século, mesmo os campos da matemática e da física (domínios de indubitável solidez se considerarmos os padrões vigentes de cientificidade) passaram a incorporar em seus conceitos a incerteza, a incompletude e $o$ inesperado.

Nossa hipótese, neste artigo, é que, na primeira metade do século 20, uma instigante confluência se dá entre as descobertas científicas e o campo das chamadas ciências do homem. Dizemos confluência por entendermos que o surgimento de uma nova concepção de sujeito leva à modificação nas concepções da ciência - como se a razão não pudesse mais ser a mesma depois de Sigmund Freud (18561939) e sua descoberta do inconsciente. Ao mesmo tempo, é por haver a possibilidade de questionar a assertividade e a objetividade da ciência que um novo conceito de sujeito pôde emergir.

Diríamos, então, que a função do inconsciente freudiano dialoga e interage com os teoremas da incerteza e do caos. Um passo a mais podemos dar ao afirmar que o inconsciente está para as ciências humanas assim como o caos está para as ciências exatas: naquele ponto, algo inusitado e inesperado acontece, ainda que não possamos apreendê-lo ou prevê-lo acuradamente. As constantes tentativas de totalização no campo da ciência, como se a elas fosse possível tudo explicar, sempre deixam, em sua trilha, um resíduo não-apreendido e, mais do que isso, para sempre inapreensível, um resto a mais que sobra das teorias e que aponta para aquilo que escapa a essas tentativas de totalização.

O insconsciente seria esse pedaço inconquistável que escapa quando tentamos apreender o humano, e as lições trazidas pela psicanálise em suas articulações ao longo do século 20 , inicialmente com Freud e posteriormente retomadas por Jacques Lacan 
(1901-1981), trouxeram para as ciências humanas a descontinuidade e a incerteza, complexificando as formas de pensar e de dizer o humano.

O caráter produtivo da dúvida, que já fora enunciada por René Descartes (1596-1650) como aquela que precede o pensamento e, portanto, a própria existência - lembremos que, antes de afirmar o penso, logo existo, Descartes instaura o se duvido, penso-, é muitas vezes negligenciado em detrimento de uma lógica fundada em certezas e respostas, e não em permanente questionamento e abertura. Em um texto sobre o tempo e as novas formas de inscrição da memória, ao perguntar sobre a lógica organizadora da contemporaneidade e por ela organizada, Jean-François Lyotard apresenta uma interessante hipótese: o que caracterizaria os tempos atuais seria a junção da técnica com a ciência, por ele chamada de tecnologos, determinante de diversas práticas sociais (cf. Lyotard, 1990). Entre elas, uma certa postura que vê no pensamento - e, portanto, no trabalho teórico - uma forma de questionar visando a chegar a seu fim: a resposta.

Lyotard estabelece um paralelo entre esta postura ocidental e as culturas não-ocidentais, em que se questiona não para se chegar a uma resposta mas para poder continuar a ser desafiado:

O que conta, na matéria que questionam, não é, de modo algum, determinar a resposta o mais rapidamente possivel, apreender e exibir algum objecto que seja válido enquanto causa do fenómeno em questão. É ser e continuar a ser questionado por ele, de se suster pela meditação 'em resposta' com ele, sem neutralizar pela explicação o seu poder de inquietação. (Lyotard, 1990, p. 81)

Ou seja, o autor aponta para o fato de que não são nas explicações sobre as relações de causa-efeito que se pode encontrar a chave para o entendimento do humano, mas sim nas relações de linguagem, que abrem sempre para uma outra possibilidade de perguntar e responder mesmo quando pensamos ter encontrado a explicação final almejada. Não podemos esquecer que toda pergunta traz 
em si suas possíveis respostas, seja no campo da matemática, seja no campo da filosofia.

A descontinuidade percebida nas ações humanas, e seu caráter de imprevisibilidade (como percebido por Freud nas chamadas produções ou formações do inconsciente: chistes, atos falhos, sonhos, sintomas), encontra ecos em regiões distantes e pode ser relacionada a uma determinada concepção de ciência, não a qualquer uma delas mas àquela que se desenvolveu no final do século 19 e início do século 20, introduzindo uma ruptura nas formas de pensar a relação verdade-realidade. A partir desse par relacional, tenta-. remos explorar neste artigo as confluências entre esses dois campos - ciência e psicanálise.

\section{Desestabilidades no campo da ciência}

É ao conceito de lógos ${ }^{2}$ que nos remetemos para começar a estabelecer um ponto de encontro entre ciência e psicanálise (e, conseqüentemente, entre as ciências exatas e as ciências humanas) a partir de um questionamento das relações entre as concepções de verdade e seus correlatos em uma suposta realidade dos fatos. Pensado a partir de Aristóteles (384-322) em sua teoria silogística e estendendo-se aos estudos da lógica matemática e simbólica (esta em busca por uma abstração radical dos conteúdos da realidade visando a aproximar-se da verdade por meio da mera forma), estamos ainda baseados na separação clássica entre mundo e linguagem. A lógica simbólica, abstraindo cada vez mais as referências ao real, chegou a fórmulas puramente matemáticas. Mundo e linguagem são concebidos como estando radicalmente separados, não havendo possibilidade de correspondência entre o conceito - constructo ${ }^{3}$ inteligível -

2. A palavra grega lógos apresenta em português inúmeras acepções. Limitamonos, aqui, a tomá-la no sentido de linguagem-discurso e pensamento-conhecimento, apontando para os termos vida, razão e linguagem de forma dinâmica $e$ constitutiva da realidade.

3. Ao utilizarmos a palavra constructo, estamos nos referindo ao modo como montamos ou interpretamos nossa amostra escolhida de dados verificáveis, para usarmos a definição proposta por Hobsbawm na introdução a seu livro Sobre história (São Paulo: Companhia das Letras, 1997). 
e a realidade - dado concreto/sensível, distanciando assim a possibilidade de verdade da apreensão da realidade.

É apenas com Emanuel Kant (1724-1804) que podemos perceber uma ruptura na história da filosofia: pensado como um possível caminho para conciliar Aristóteles e a lógica matemático-simbólica, Kant estabelece condições a priori para a intelecção, inaugurando, na lógica, a distância entre a linguagem e a realidade não na forma de um corte radical mas afirmando a correspondência entre mundo e realidade (ainda que não de forma direta, mas mediada) como condição para o estabelecimento de critérios de verdade em relação à realidade.

Em Kant, os modos pelos quais vemos os fenômenos correspondem ao real; por essa razão, podemos afirmar que $o$ real é racional: vemos o mundo a partir de categorias a priori - o mundo é por elas criado -, e estas categorias a partir das quais vemos o mundo encontram-se com o real. A razão operaria, desse modo, a partir de categorias a priori para o conhecimento da realidade.

Relembrando o método dedutivo - que, em linhas gerais, vai do geral ao particular - e o método indutivo, que vai do particular ao geral, como métodos investigativos e formas de raciocínio, Kant coloca-se como uma terceira possibilidade ao definir os juízos sintético-analíticos. Para Kant, a dedução seria uma mera tautologia (afirmaria apenas uma verdade que já está contida nas premissas) e a indução careceria de fundamentos conceituais, não podendo garantir o grau de certeza de suas afirmações. Dessa forma, buscou construir um método de conhecimento tão preciso quanto a dedução, mas que abrisse espaço para a criação e o surgimento de novos conceitos, como ocorre na indução.

Essa terceira via - entre a dedução e a indução, e para além delas - vem sendo buscada desde Aristóteles com o nome de método hipotético-dedutivo e, por aproximação, pode ser comparada ao que Charles Peirce (1839-1914) chama de abdução - uma possibilidade de estabelecer o raciocínio criativo como método, baseada no formulação de hipóteses a serem refutadas ou confirmadas, colocandose portanto no limite das probabilidades. Em Kant, essa terceira possibilidade foi sintetizada em sua concepção de juízos sintéticos 
a priori, uma combinação de conhecimentos puros com conhecimentos empíricos.

A partir de Kant, principalmente com a fenomenologia de Edmund Husserl ${ }^{4}$ (1859-1938) e com os jogos de linguagem de Ludwig Wittgenstein ${ }^{5}$ (1889-1951), começa a se romper a dicotomia realidade-linguagem e abre-se a possibilidade de pensar não em $o$ mundo e a linguagem mas em o mundo é linguagem, passando da concepção de representação para a de apresentação do mundo, como tão bem explorado por José Arthur Giannotti em seus estudos sobre Wittgenstein (cf. Giannotti, 1995).

De Husserl a Wittgenstein, sem esquecer George Boole (1815-1864), Gottlob Frege (1848-1925) e Bertrand Russell (18721970), é toda uma tradição do pensamento e da ciência - e, consequientemente, da própria constituição de sociedade - que gira sobre si mesma e se desloca. Na filosofia, podemos afirmar que Husserl foi quem continuou aquilo que Kant começara, levando à radicalidade a impossibilidade de se separar o mundo da linguagem. De lá para cá esse tema tem sido pesquisado por diversos filósofos (como os contemporâneos Jacques Derrida e Gilles Deleuze) e conduziu à idéia de uma incerteza básica constituinte da realidade e do próprio sujeito (como veremos em Freud). Se, por um lado, podemos afirmar não

4. De acordo com Chauí em seu Convite à filosofia (São Paulo: Brasiliense, 1994), a fenomenologia introduziu a noção de essência ou significação como um conceito que permite diferenciar internamente uma realidade de outras, encontrando o sentido, a forma, as propriedades e a origem de tal realidade. Dividiu, por exemplo, a essência natureza da essência homem, e no homem as essências psíquico, social, histórico, cultural etc., garantindo às ciências humanas a validade de seus campos de investigação (psicologia, história, sociologia, antropologia, lingüística, economia) e a existência e especificidade de seus objetos. Cada uma das ciências humanas não deveria mais dar conta do conhecimento como um todo, buscando explicar exaustivamente todas as relações humanas e o mundo existente a partir de seus próprios conceitos, mas estaria relacionada à especificidade de seus projetos e investigações a partir de métodos e conceitos também específicos.

5. Em relação às teorias da linguagem, no lugar de remeterem aos enunciados dos discursos tais jogos remetem à instância da enunciação (cf. Benveniste, 1989), fazendo-se e desfazendo-se em ato; configuram-se como ligaçöes entre elementos que se fazem para logo se desfazer, em um dado momento, articulando laços sociais por meio dos discursos. 
ser possível à linguagem recobrir integralmente um suposto mundo que a antecede, devemos afirmar, por outro, não ser possível à realidade constituir-se enquanto tal a não ser no incessante jogo de proximidade e distanciamento em relação à linguagem, não existindo fora dela - daí sua imponderabilidade.

Tal impossibilidade é examinada por Jorge Luis Borges no fragmento "Del rigor en la ciencia" (exaustivamente comentado por estudiosos das mais diversas áreas), em que os cartógrafos de um determinado reino desenham um mapa tão detalhado que acaba por cobrir exatamente o território ${ }^{6}$. Para representar com fidelidade o reino inteiro e agradar ao rei, o mapa deve ter o tamanho exato da cidade existente, criando uma impossibilidade: ao ser cópia fiel, deixa de ser uma reprodução imaginária da cidade e passaria a ser o próprio objeto que tentava representar ${ }^{7}$.

Trata-se, pois, da questão do próprio estatuto da linguagem e de sua inseparabilidade em relação ao mundo. Afirmar, como já

6. En aquel Imperio, el Arte de la Cartografía logró tal perfección que el Mapa de una sola Provincia ocupaba toda una ciudad, y el Mapa del Imperio toda una provincia. Con el tiempo, estos Mapas Desmesurados no satisfacieron y los Colegios de Cartógrafos levantaron un Mapa del Imperio, que tenia el tamaño del Imperio y coincidía puntualmente con él. Menos Adictas al Estudio de la Cartografía, las Generaciones siguientes entendieron que esse dilatado Mapa era inútil y no sin Impiedad lo entregaron a las Inclemencias del Sol y de los Inviemos. En los Desiertos del Oeste perduran despedazadas Ruinas del Mapa habitadas por Animales y por Mendigos; en todo el País no hay otra reliquia de las Disciplinas Cartográficas (Borges, 1961, p. 103).

7. O referido fragmento foi atribuído por Borges a Suárez Miranda na obra intitulada Viajes de varones prudentes (libro cuarto, cap. XIV, Lérida, 1658). Em seu livro Simulacros e simulação, Baudrillard refere-se ao conto como uma antiga alegoria da simulaçāo que teria se tornado apenas um simulacro de segunda categoria, já que para ele hoje a abstração não é a do mapa, do duplo, do espelho ou do conceito. A simulação já não é a simulação de um território, de um ser referencial, de uma substância. É a geração pelos modelos de um real sem origem nem realidade: hiper-real (Baudrillard, 1991, p. 8). Ao contrário do conto de Borges, são os vestígios do real - e não os vestígios do mapa - que sobrevivem não é o território que precede o mapa, mas o mapa precede o território. Sem querer discutir as idéias de Baudrillard, afirmamos, ao contrário, que não se pode recobrir com representações uma suposta realidade antecedente a elas nāo por habitarmos um mundo de simulações mas sim devido ao próprio caráter dinâmico de construção da realidade pela linguagem: ao fazer o mapa, estaríamos traçando a própria realidade. 
fizemos outras vezes, que o mundo é linguagem significa dizer que o mesmo não existe fora dela, apontando para o fato de que há que aceitar um certo grau de incerteza como constituinte da realidade e incorporá-lo - o mundo é criado pela linguagem e tal constructo não corresponde exatamente a um suposto real, mas está no lugar de. A esse conceito de linguagem, fazemos corresponder uma certa concepção de ciência, o que nos conduz agora a uma discussão metodológica. Ao falar no discurso articulador da contemporaneidade - o discurso tecnológico, para usarmos os termos de Lyotard -, não podemos nos furtar em falar de seu já mencionado encontro com a ciência. Gostaríamos então, nesse momento, de delimitar o ponto a partir do qual vislumbramos a ciência, aqui tomada enquanto discurso e, portanto, como articuladora de realidades sociais.

Evocamos agora o critério de falseabilismo de Popper, as rupturas epistemológicas de Kuhn, a noção de impreditibilidade de Poincaré, o teorema da incompletude de Gödel, o princípio da incerteza de Heisenberg, a teoria do caos de Thom, as formas fractais de Mandelbrot. Sem querer esgotar a extensa discussão dos métodos e da pesquisa científica a partir da filosofia da ciência, arriscamo-nos a lançar algumas idéias sobre essas concepções. Pretendemos, a partir delas, estabelecer um paralelo com as noções de pesquisa e produção de conhecimento nas ciências chamadas do homem até chegarmos ao conceito de inconsciente conforme proposto por Freud e retomado por Lacan. Todos esses pensadores representam momentos de significativas rupturas na primeira metade do século 20 , verdadeiras odisséias do pensamento, apontando para um certo espírito do tempo.

Vejamos, então, uma síntese das teorias que nos interessam nesse momento, começando pelo debate entre dois filósofos da ciência: Popper e Kuhn. $O$ contraponto entre eles pode ser estabelecido a partir do par falsificação x revolução, referindo-se a dois conceitos básicos presentes em cada um dos autores.

Karl R. Popper (1902-1994), filósofo inglês de origem austríaca, elegeu como critério para o estabelecimento de teorias científicas não que elas sejam verificáveis mas que sejam falseáveis, testáveis. É esse critério, o falseabilismo ou falsificacionismo, o 
critério de demarcação na concepção popperiana. À ciência caberia o papel de refutar teorias incorretas: um enunciado é refutável se e somente se é logicamente incompatível com ao menos um enunciado básico já confirmado, o que faz com que uma hipótese possa tornar-se testável. Dessa forma, postulados que não pudessem ser refutados não seriam suficientes para as ciências. Popper acrescentou às teorias seu caráter explicativo, ou seja, considerava as teorias como redes lançadas ao mundo para tentar capturá-lo, racionalizá-lo.

No livro Conjecturas e refutações (1963), Popper afirma que só é possível compreender a realidade a partir dos problemas que se apresentam para serem solucionados e das teorias científicas que formam o que ele denomina de conjecturas genuinas, ou seja, suposições altamente informativas acerca do mundo, ainda que não verificáveis:

Aceito a concepção (implícita na teoria clássica da verdade: a teoria da correspondência) de que deveríamos chamar real a um estado de coisas se, $e$ somente se, o enunciado que $o$ descreve é verdadeiro. Mas, seria um erro grave concluir disso que a incerteza de uma teoria, isto é, seu caráter hipotético ou conjetural, diminua de alguma maneira sua pretensão implícita de descrever alguma coisa real. Pois, todo enunciado $s$ é equivalente a um enunciado que pretende que sé verdadeiro. E, com relação ao fato de s ser uma conjetura, devemos lembrar que, antes de mais nada, uma conjetura pode ser verdadeira, e deste modo descrever um estado de coisas real. Em segundo lugar, se ela é falsa, então contradiz algum estado de coisas real (descrito por sua negação verdadeira). Além do mais, se testamos nossa conjetura, e conseguimos falseá-la, vemos claramente que existia uma realidade - alguma coisa com a qual ela poderia entrar em choque. Nossos falseamentos indicam, portanto, os pontos em que tocamos a realidade, por assim dizer. E nossa última e melhor teoria sempre é uma tentativa de incorporar todos os falseamentos já encontrados no campo, explicando-os da maneira mais testável possivel. (Popper, 1982, pp. 147-148) 
Popper afasta das teorias a possibilidade de sua verificação empírica, já que recusa a inviolabilidade dos seus enunciados básicos. Em resumo, para Popper as teorias deveriam ser tomadas como hipóteses empíricas falseáveis e não como meras convenções, implicando em uma constante substituição de teorias científicas por outras de maior amplitude e com maior capacidade explicatória. Em Popper, portanto, a questão da verdade deixa de ser a exata correspondência entre um conceito e a realidade e passa a ser vista como uma questão da coerência interna entre esses conceitos. As mudanças científicas seriam uma conseqüência da concepção de verdade como coerência teórica, e por isso as teorias devem ser avaliadas pela possibilidade de serem falseadas, ou seja, devem estar abertas a fatos novos. Em oposição ao verdadeiro, o falso seria a perda de coerência de uma teoria, a existência de contradições entre seus princípios ou conceitos, permitindo que as teorias sejam permanentemente corrigidas.

Opondo-se a Popper, Thomas Kuhn (1922-1996), filósofo e historiador da ciência norte-americano, apresenta uma outra forma de aproximação ao problema, afirmando que nunca houve um caso sequer em que uma teoria pudesse ser refutada por fatos científicos. Um fato novo não pode assegurar a coerência interna de uma teoria; ao contrário, aponta para suas contradições, fazendo com que ocorra uma mudança radical. Essas mudanças foram denominadas por Kuhn de rupturas epistemológicas ou revoluções científicas, provocando o surgimento de novas teorias verdadeiras. Dessa forma, é o critério de verdade (qualquer que seja ele), e não o de falsidade, que guiaria a pesquisa científica.

De acordo com Kuhn, podemos dividir a atividade científica em duas espécies distintas de fases que se alternam: períodos de revolução científica, nos quais surge a ciência extraordinária, e períodos interpostos entre duas revoluções, ou períodos de ciência normal. Os períodos de ciência normal caracterizam-se pela existência de comunidades científicas e pela adoção de paradigmas, ou seja, de determinados conjuntos de métodos, princípios e conceitos básicos, além de exemplos orientadores, todos inquestionáveis durante uma tradição de pesquisa estabelecida. 
Essas pesquisas, baseadas em paradigmas compartilhados, orientam-se para a solução de problemas (os famosos puzzles) reconhecidos pela comunidade científica como relevantes; pode-se dizer então que (...) a pesquisa científica normal está dirigida (somente) para a articulação daqueles fenômenos e teorias já fornecidos pelo paradigma. (Kuhn, 1975, p. 39)

A ciência extraordinária surge quando essa estrutura de aparência inabalável - a ciência normal - começa a estremecer, quando ocorre um período prolongado de crise do paradigma, em meio a uma revolução científica, na qual o paradigma vigente será inteiramente substituído por outro. Para que esse processo possa ser melhor compreendido, tomemos uma descrição do próprio Kuhn:

As áreas investigadas pela ciência normal são certamente minúsculas; ela restringe drasticamente a visão do cientista. Mas essas restrições, nascidas da confiança no paradigma, revelam-se essenciais para o desenvolvimento da ciência. Ao concentrar a atenção numa faixa de problemas relativamente esotéricos, o paradigma força os cientistas a investigar alguma parcela da natureza com uma profundidade e de maneira tão detalhada que de outro modo seriam inimagináveis. $E$ a ciência normal possui um mecanismo interno que assegura o relaxamento das restrições que limitam a pesquisa, toda vez que o paradigma do qual derivam deixa de funcionar efetivamente. Nessa altura os cientistas começam a comportar-se de maneira diferente e a natureza dos problemas de pesquisa muda. No intervalo, entretanto, durante o qual o paradigma foi bem sucedido, os membros da profissão terão resolvido problemas quem mal poderiam ter imaginado e cuja solução nunca teriam empreendido sem o comprometimento com o paradigma. E pelo menos parte dessas realizações sempre demonstra ser permanente. (Kuhn, 1975, p. 45)

$\mathrm{O}$ relaxamento das restrições que limitam a pesquisa, o comportamento diferente dos cientistas e a mudança de natureza dos problemas de pesquisa correspondem ao período da ciência 
extraordinária, período em que pesquisadores descontentes com a gravidade das anomalias acumuladas no interior do paradigma vigente entram em conflito com a tradição e interrompem o processo de desenvolvimento que - como fica claro no trecho acima citado - é restrito aos limites do paradigma. Note-se, ainda, o grau de interdependência entre os conceitos de comunidade científica e de ciência normal na teoria de Kuhn.

Essa passagem de um paradigma a outro de maneira alguma se aproxima do que Popper descreve como uma mudança de teorias. Para Kuhn, a mudança não se dá a partir de uma escolha externa entre teorias mas de forma instantânea - ao menos aos olhos do pesquisador -, já que deve estar necessariamente implicada em alguma das teorias.

Apesar de suas diferentes concepções, Popper e Kuhn introduzem no universo da ciência uma certa idéia de descontinuidade e diferença em oposição à idéia de linearidade ou progresso científicos. Daí podermos afirmar que as diferenças entre as diversas teorias científicas são fruto não de seu aperfeiçoamento em relação a um ideal preestabelecido de verdade, ou de uma maneira melhor ou mais evoluída de fazer ciência, mas de mudanças de concepção e diferentes maneiras de construir e conceber os objetos científicos e, conseqüentemente, as teorias e metodologias sobre eles elaboradas. Em cada teoria, portanto, o conceito de natureza e de homem nela pressuposto é diferenciado, assim como os métodos e os princípios adotados, e os próprios objetos que se quer conhecer. A noção de progresso ou evolução, de uma suposta linearidade e temporalidade na sucessão de teorias, é assim fortemente questionada. Tal questionamento se estende para além dos limites e alcances da filosofia da ciência. Cientistas e pesquisadores das áreas de física e matemática demonstraram ao longo do século outros aspectos que vêm a confirmar as brechas e descontinuidades presentes no processo de conhecimento.

O matemático e físico francês Jules Henri Poincaré (18541912), antecipando essas questões, ainda no século 19 apontou para o grau de impreditibilidade em certos sistemas matemáticos: 
Nossos antepassados descobriram, há muito tempo, que o futuro era dificil de prever e que pequenas causas podiam ter grandes efeitos. O que é relativamente novo é a demonstração de que, para certos sistemas, uma pequena mudança na condição inicial leva habitualmente a uma mudança tal da evolução ulterior do sistema que as predições a longo prazo se tornam completamente vãs. (Ruelle, 1993, p. 65)

Um pouco de incerteza inicial - em sistemas que dependem das condições iniciais - levaria à impreditibilidade a longo prazo sobre o futuro do sistema. Com isso, lançaria o que podemos afirmar serem as bases remotas da moderna teoria do caos.

Até o início do século, a matemática era pensada como a única ciência exata, da qual as outras ciências deveriam se aproximar o máximo possível para que pudessem ter assegurado o grau de certeza de seus conhecimentos. Com Poincaré, surge a idéia de que algo está sempre escapando ao conhecimento e que, portanto, nem a matemática poderia dar conta da totalidade do conhecimento. A partir daí, outras posições foram se formando, como a de Hans-Georg Gadamer (1900), filósofo alemão, sobre a questão da interpretação, e a de Paul Feyerabend (1924-1994), físico e filósofo inglês, sobre o fim dos métodos clássicos de conhecimento (que veremos adiante), além dos pensadores a seguir.

Também no campo da física, o alemão Werner Heisenberg (1901-1976) introduz, com o princípio da incerteza, a idéia de imponderabilidade no campo da ciência. Com esse princípio, pretendia criticar uma certa noção de determinismo presente na física clássica, que acreditava poder estender a idéia de causalidade - de que a cada efeito corresponde uma causa - indefinidamente, na medida em que pequenas alterações no processo de observação e aferição dos fenômenos físicos alterariam seus resultados (Ruelle, 1993: 22). Dessa forma, mesmo pequenas causas - muitas vezes imperceptíveis e, por isso, atribuídas ao acaso ${ }^{8}$ - podem alterar os resultados

8. Nas palavras de Poincaré, uma causa muito pequena, que nos escapa, determina um efeito considerável que não podemos deixar de ver, e então dizemos que esse efeito se deve ao acaso (apud Ruelle, 1993, p. 67).

$\overline{\text { Significação } 21 \cdot 184}$ 
de um experimento. Segundo Heisenberg, portanto, em alguns campos da física podemos possuir apenas um conhecimento estatístico ou probabilístico sobre determinados fenômenos, como por exemplo a medição da posição das partículas que compõem o átomo, ou seja: um resultado específico não corresponde necessariamente a uma determinada causa; é apenas estatisticamente provável que assim seja.

Kurt Gödel (1906-1978), lógico austríaco, tem entre suas contribuições mais importantes para a lógica os teoremas da incompletude (Ruelle, 1993: 197). A relação estabelecida por Gödel se dá entre os eixos completude e certeza. Afirmando ser impossível obter um alto grau de completude e um alto grau de certeza na elaboração de uma teoria, Gödel aponta para um paradoxo na atividade científica. A solução a esse paradoxo por ele ensejada afirma que ao circunscrever o campo de pesquisa tem-se certeza, mas também incompletude (por fechar e limitar o campo, deixando de fora inúmeros elementos); ao abrir o campo, por sua vez, tem-se completude (tudo estaria incluído), mas perde-se certeza. Quanto mais certezas, portanto, mais incompleto o campo de pesquisa e, por essa razão, sujeito às variações e oscilações não previstas inicialmente no sistema explicativo e teórico construído para lhe dar sustentação.

René Frederic Thom (1923), matemático francês, fundou a chamada teoria do caos. A partir da noção de topologia, concebe um substrato em um conjunto aberto de um espaço euclideano de dimensão finita $U$. Nesse espaço, $u$ é regular se em cada ponto $u$ ' próximo a ele aquilo que está em $u$ ' possui a mesma aparência qualitativa que em $u$. O ponto $u$ é regular se uma esferazinha de centro $u$, muito pequena, não contém qualquer acidente rigorosamente interessante - nela nada acontece. O conjunto de tais pontos regulares é um aberto em $U$. Representa-se, a seguir, o complemento $K$ do conjunto $U$, em que $K$ seja o conjunto fechado dos pontos de catástrofe (caos). Se $v$ é um ponto em $K$, em toda esferazinha de centro $v$, alguma coisa acontece.

A palavra catástrofe (caos), portanto, não tem a conotação negativa que apresenta na linguagem cotidiana - simplesmente em cada ponto $v$ do conjunto catastrófico $K$, as coisas mudam. Tal 
distinção entre pontos regulares e catastróficos é relativa, depende da acuidade dos meios de observação. Nas bordas, os pontos regulares e caóticos se misturam, como nas bordas não nítidas entre uma cor do arco-íris e outra, difíceis de serem reconhecidas e identificadas (Thom, 1985: 11-28).

Em relação à teoria do caos, uma interessante observação foi feita por Thom a respeito do problema do determinismo em sua polêmica com Ilya Prigogine ${ }^{9}$. Thom afirma que

já que a natureza da ciência é formular leis, todo estudo científico da evolução do Universo desembocará, necessariamente, numa formulação determinista. Observemos, porém, que talvez não se trate do determinismo de $P$. $S$. Laplace ${ }^{10}$, mas, por exemplo, de leis 'deterministas' que governem a evolução de distribuições de probabilidades. (Ruelle, 1993, p. 43)

Segundo ele, não se pode escapar a um certo grau de determinismo sempre que se procura por leis universais e gerais,

9. A esse respeito, remetemos ao livro O fim das certezas (São Paulo: Unesp, 1996), de Prigogine, em que são examinadas as relaçōes entre o tempo, o caos e as leis da natureza a partir de algumas questōes que têm sido formuladas desde as origens do pensamento ocidental, tais como: $O$ universo é regido por leis deterministas? Qual é o papel do nosso tempo?. Considerando as contribuições da física e da matemática, do caos e da instabilidade, o livro busca responder tais questões a partir de novas perspectivas.

10. Conforme formulação de Laplace: Uma inteligência que, para um instante dado, conhecesse todas as forças de que está animada a natureza, e a situação rèspectiva dos seres que a compõem, e se além disso essa inteligência fosse ampla o suficiente para submeter esses dados à análise, ela abarcaria na mesma fórmula os movimentos dos maiores corpos do Universo e os do mais leve átomo: nada seria incerto para ela, e tanto o futuro como o passado estariam presentes aos seus olhos. $O$ espirito humano oferece, na perfeição que foi capaz de dar à astronomia, um pequeno esboço dessa inteligência (P. S. Laplace, Essai philosophique sur les probabilités, Paris: Courcier, 1814. Apud Ruelle, 1993, p. 42). Lembramos aqui as referências ao tecnologos de Lyotard (1990) em relação à memória e suas inscrições e à ambição de algumas pesquisas sobre inteligência artificial de construção do super-cérebro - aquele que possa tudo saber a um só tempo, como a mônada de Leibniz (ver artigo de Michael Brooks traduzido no jornal Folha de S. Paulo, caderno mais!, 02/07/2000). 
ainda que tal determinismo esteja localizado não no campo das certezas mas das probabilidades.

Finalmente, o matemático polonês Benoit Mandelbrot (1924) traz uma instigante contribuição da ciência ao mundo das artes, lançando um caloroso debate sobre a questão das artes digitais em termos de seu próprio estatuto e validade. Ao pesquisar equações diferenciais matemáticas em computador, Mandelbrot deparou-se com formas geométricas tridimensionais às quais deu o nome de fractais. Tais figuras, geradas por programas de computador, equivalem a formas do mundo concreto que diferem dos quadrados, esferas e pirâmides perfeitos das figuras geométricas bidimensionais:

Os fractais são formas geométricas que são igualmente complexas nos seus detalhes e na sua forma geral. Isto é, se um pedaço de fractal for devidamente aumentado para tornarse do mesmo tamanho que o todo, deveria parecer-se com o todo, ainda que tivesse que sofrer algumas pequenas deformações. (Mandelbrot, 1993, p. 197)

O mais famoso exemplo da geometria fractal de Mandelbrot é a resposta à pergunta: quão extensa é a costa? Se você tivesse de caminhar ao longo da costa, medindo a distância com um compasso calibrado para um metro, obteria uma resposta, e com outro compasso calibrado para $30 \mathrm{~cm}$, a resposta seria maior, porque uma parte maior de irregularidades poderia ser medida. Mandelbrot descobriu que não existe limite teórico para esse processo. Com isso, demonstrou que de informações simples e repetitivas podem surgir padrões complexos e variados como as instruções contidas nos genes, que geram sistemas complexos no organismo humano.

Com os fractais, Mandelbrot relaciona a matemática às formas usuais da arte, afirmando que a arte fractal exemplifica alguma coisa completamente nova, na qual a atuação mútua de ordem e surpresa não precisa ser o resultado nem de imitação da natureza nem da criatividade humana: pode também ter uma fonte inteiramente diferente. De fato, fórmulas matemáticas extremamente simples que parecem completamente estéreis podem dar vida, por 
assim dizer, a uma quantidade de estruturas gráficas enorme. $O$ gosto do artista só pode afetar a seleção de fórmulas a serem desenhadas, o enquadramento e o desenho. (Mandelbrot, 1993: 200) Por analogia, podemos afirmar que os fractais estão para a arte assim como os teoremas anteriormente apresentados estão para a ciência: apresentam uma margem de abertura e de imprevisibilidade, uma combinação de ordem e de caos.

O físico Marcelo Gleiser, em artigo publicado na Folha de S. Paulo, assim define o caos:

Essa sensibilidade às condições iniciais é uma das marcas registradas dos sistemas caóticos. Contrariamente ao uso comum da palavra, que significa o oposto de ordem, caos em um sistema físico representa um comportamento que, apesar de complexo, não é inteiramente desorganizado. Há uma persistência no comportamento do sistema, uma obediência a certos vínculos, que não existe em um sistema aleatório. (Gleiser, 2000, p. 29)

Como exemplo de sistema caótico, o autor menciona o clima e a dificuldade em prever suas variações, pois qualquer alteração em um determinado local pode afetar as condições climáticas de outro, sendo impossível conhecer todos os detalhes envolvidos neste processo embora ele não seja um processo aleatório. Nas palavras de Gleiser, há um limite mesmo para o caos climático. (Gleiser, 2000, p. 29)

É esse comportamento do clima que pode ser estendido a outros sistemas, chamados complexos ou não-lineares. Ao contrário dos sistemas lineares (ou regulares), em que a resposta é proporcional ao estímulo (princípio presente, por exemplo, na psicologia behaviorista), os sistemas complexos possuem a propriedade de responder a estímulos de forma irregular. Trata-se aqui do princípio da incerteza, apresentado por Heisenberg, e da concepção fundante da teoria do caos: um pequeno estímulo pode causar uma grande resposta, fazendo com que a não-linearidade e a forte dependência das condições iniciais sejam dois elementos fundamentais dos sistemas complexos (Gleiser, 2000, p. 29). 
A partir das teorias da física e da matemática contemporâneas, gostaríamos de questionar, no campo das ciências humanas, concepções deterministas ou reducionistas baseadas em certezas e na capacidade de tudo prever. Se mesmo um sistema simples pode ter comportamentos complexos, o que dizer das estruturas e relações ensejadas pelo humano?

Gleiser afirma que a propriedade mais importante dos sistemas não-lineares é a emergência da ordem a partir da desordem.(Gleiser, 2000: 29) Ao pensarmos nessa propriedade, podemos nos voltar às teorias da linguagem. A perspectiva de construção do mundo pela linguagem aponta para uma abertura, uma espécie de terceira alternativa, da qual deriva a possibilidade de pensarmos a incompletude e o caos, a margem do desconhecido e do imprevisível. Tal questão nos remete uma vez mais à pergunta sobre qual o discurso articulador da contemporaneidade - que a organiza e é por ela organizado.

Uma postura crítica interessante nos é oferecida por Feyerabend, físico e filósofo da ciência que, desde a década de 60 , tem refletido sobre as questões relativas aos fundamentos da ciência e à epistemologia científica. Embora seja visto por muitos como defensor do relativismo e do anarquismo intelectual, suas idéias são pertinentes se considerarmos o campo no qual estamos inseridos as ciências humanas - devido à pluralidade que lhes é constituinte.

Dentre suas muitas contribuições, destacamos a proposta de uma metodologia pluralista em relação à pesquisa científica, seja ela em ciências exatas ou humanas. A produção do conhecimento é vista como um processo permanente, no qual o trabalho do cientista não seria confrontar idéias e teorias com uma suposta experiência dos fatos mas, sobretudo, confrontar idéias com idéias, teorias com teorias, textos com outros textos:

Knowledge so conceived is not a series of self-consistent theories that converges towards an ideal view; it is not a gradual approach to the truth. It is rather an ever increasing ocean of mutually incompatible alternatives, each single theory, each fairy-tale, each myth that is part of the collection 
forcing the others into greater articulation (...). Nothing is ever settled, no view can ever be omitted from a comprehensive account. (Feyerabend, 2000, p. 21)

Para além do que denomina receitas metodológicas, Feyerabend propõe o princípio do tudo vale: Tendo a metodologia pluralista como meta, seus esforços caminhariam no sentido de estabelecer alternativas a uma abordagem fundamentalista do saber, registrada, na ênfase do autor, na 'adoração dos fatos', na crença em um poder de desvelamento - e revelação - da experiência. (Rocha, 1998: 2). Mais do que estabelecer certezas, tal postura aponta para a necessidade de adotar a dúvida - o questionamento sistemático - como postura metodológica que contemple o aspecto de invenção e criação presente na pesquisa científica:

Parece-me que uma atividade cujo caráter humano pode ser visto por todos é preferivel a uma atividade que se afigura "objetiva" e inacessivel às ações e aos desejos humanos. As ciências, afinal de contas, são nossa própria criação, incluindo todos os severos padrões que elas parecem impor-nos. É bom ter sempre presente o fato de que a ciência, como hoje a conhecemos, não é inelutável e que nós podemos construir um mundo em que ela não desempenhe papel algum. (Feyerabend, 1979, p. 281)

Feyerabend também estabelece - ainda que a partir de outros termos - as margens (ou limites) da pesquisa e do conhecimento científicos. É nesse sentido que nos ajuda a pensar as relações entre dogmatismo e relativismo, apontando para alguns dos pressupostos metodológicos pertinentes para nosso campo de trabalho. Talvez uma idéia interessante seja a de que a ciência (ou a pesquisa científica) não seja conduzida pela linearidade de uma única verdade final a ser alcançada, mas tenha sempre ao fundo uma possibilidade de verdade, só que cambiante, mutável. Uma verdade ao fundo, só que não-linear porque nem sempre será a mesma. Mas qual seria então essa verdade? 
Ao tratar do relativismo, Feyerabend estabelece uma distinção entre o relativismo prático (que caracteriza como oportunista por visar a fins específicos), o relativismo democrático (o convívio de diferentes opiniões ou teorias) e o relativismo epistêmico (que assinala o tudo vale mas não o vale tudo, já que seria inerente à própria ciência). Ao contrário da crítica de Popper, que afirmara que o relativismo é a posição de que qualquer coisa pode ser afirmada, ou quase tudo, e por conseguinte nada (Feyerabend, 1991, p. 99) - e que, assim sendo, a verdade perde seu significado -, Feyerabend propõe uma outra concepção, na qual o relativismo não seria a simples escolha entre teorias contrárias ou o apagamento da verdade objetiva, impossibilitando a escolha entre idéias alternativas.

Trata-se, assim, não de propor uma outra definição mas de deslocar o eixo da própria questão. Em vez de perguntar se a verdade é ou não uma noção objetiva, se a prática científica é racional, de que forma a realidade depende de nossa percepção, o relativismo afasta-se dessas questões, afirmando que o que está certo a partir de determinados pressupostos pode não estar certo se outros critérios forem tomados, revelando as lacunas do objetivismo sem com isso significar uma arbitrariedade absoluta.

Os limites estão sendo colocados em relação ao objetivismo herdado da ciência clássica, que determinou grande parte das ciências exatas até o início do século 20 , já que as ciências que dizem respeito ao homem dificilmente podem extrair a verdade da experiência objetiva, se entendemos objetividade no mesmo sentido fundante da ciência física.(Freitas, 1992b, p. 10) Atentemos à palavra fundante, que aponta para o caráter clássico de tal definição. Ao se tentar tomar o homem como objeto o que se alcança são experiências geralmente frustrantes, já que há sempre um ponto decisivo que escapa à objetivação e desfaz, na escapada, premissas e certezas, projeções e controles (Freitas, 1992b, p. 10).

A partir da concepção da ciência como uma atividade baseada em acertos e erros, tentativas e recomeços, Peirce amplia as tradições dos métodos dedutivo e indutivo, sugerindo um modelo conjectural ou hipotético-abdutivo, a abdução, cujo principal mérito 
é considerar a possibilidade de interferência de fatos que podem fugir à observação, mesmo sob rígido controle.

Abdução é o processo de formação de uma hipótese explanatória. É a única operação lógica que apresenta uma idéia nova, pois a indução nada faz além de determinar um valor, e a dedução meramente desenvolve as conseqüências necessárias de uma hipótese pura. (Peirce, 1977, p. 220, § 171)

Com relação à indução e à dedução, Peirce continua: $A$ dedução prova que algo deve ser; $a$ indução mostra que alguma coisa é realmente operativa; a abdução simplesmente sugere que alguma coisa pode ser (Peirce, 1977, p. 220, § 171). As considerações apontadas por Peirce não podem ser negligenciadas, já que instauram no campo da ciência a probabilidade e o falibilismo.

Se pensarmos no lógos contemporâneo de Lyotard - o tecnologos -, podemos relacioná-lo a uma mudança na concepção de ciência e na concepção de sujeito (cf. Koyré, 1982). É por essa trilha que, da ciência, chegamos a Freud e sua descoberta radical: o inconsciente colocado como aquele que habita e constitui o humano.

\section{Desestabilidades no campo do humano}

Da ciência como permanente constructo a partir da linguagem - portanto, sempre em estreita relação com o panorama histórico e social nas artes e na filosofia - estendemos as reflexões anteriormente ensejadas a outros campos do conhecimento. A confluência entre eles, voltamos a afirmar, faz-se pela linguagem. Em relação à linguagem, a lógica que se configura como possibilidade discursiva é a lógica do significante, articulada a partir de seus dois eixos (cf. Lemaire, 1989). Como na proposta freudiana de que os sonhos seriam estruturados como a linguagem e operariam por meio de condensações (metáforas) e deslocamentos (metonímias), as cadeias discursivas - a linguagem - é que engendram a própria realidade 
por meio dos eixos paradigmático (das escolhas, operando sincronicamente por substituição) e sintagmático (das combinações, operando diacronicamente por contigüidade) (cf. Jakobson, 1965).

O livro A interpretação dos sonhos, lançado em 1900, já fez cem anos. Podemos, portanto, inseri-lo no mesmo quadro referencial anteriormente apresentado. Algumas evidências apontam nessa direção, como o desenvolvimento, também em 1900, da teoria dos quanta pelo físico alemão Max Planck (1858-1947), que introduz a idéia da transmissão de energia em pacotes pré-definidos chamados quanta. Uma relação entre a física quântica e a clínica psicanalítica pode ser ensaiada:

Pensamos que o campo da física quântica traz, realmente, um modelo que pode servir para pensar a clínica. Do ponto de vista consciente achamos que podemos ter sempre certezas bem estabelecidas, sem falhas, dentro de uma lógica implacável, de forma a podermos dar conta do que está acontecendo em nós. (Corrêa, 2001, p. 17)

Acrescentaríamos ainda: não apenas pretendemos dar conta de forma definitiva e coesa do que está acontecendo em nós mas também do que está acontecendo ao nosso redor, e as teorias ensejadas pelas ciências humanas são vistas como importantes aparatos de controle e previsão.

Ao afirmar o homem não é mais senhor em sua própria casa, o que Freud desestabiliza são as próprias bases das ciências humanas. Sua releitura por Lacan levaria à concepção de sujeito como um significante para outro significante, o falante/desejante marcado pela falta, inscrição primordial. A analogia à física quântica pode ser mais uma vez evocada:

Na física quântica, o fato de que não se possa pontuar o elétron, isto é, que não se possa saber ao mesmo tempo em que ponto ele está e qual sua velocidade neste momento, que não se possa saber estas duas coordenadas simultaneamente, e que esta impossibilidade seja considerada como definitiva, até 
nova ordem, isso nos lembra algo do estatuto do inconsciente freudiano, que só pode ser apreendido indiretamente, isto é, a partir de suas formações. (Corrêa, 2001, p. 17)

Podemos ousar a afirmação, portanto, de que quem que primeiramente introduz, nas ciências humanas, as teorias da física e da matemática acima expostas é Freud; ele, e talvez ninguém mais em outra área das ciências humanas na época, incorpora, prevê e trata daquilo que não se completa, daquilo que não pode jamais cessar, daquilo que falta (denominação posteriormente cunhada por Lacan) e, dessa forma, permanece sempre como resto. Freud incorpora às ciências humanas, naquele momento, a discussão crucial das ciências exatas - que se estenderia por todo o século 20 -, aquela que nenhum outro pensador havia incorporado de forma tão radical ao tratar do humano e, ao fazê-lo, lança sobre as teorias científicas novas possibilidades.

Dessa forma, lançaríamos aqui a hipótese de que o conceito de inconsciente está para Freud assim como a impreditibilidade está para Poincaré, o princípio da incerteza está para Heisenberg, o teorema da incompletude para Gödel, a teoria do caos para Thom, a geometria fractal para Mandelbrot e, avançando um pouco mais, o objeto pequeno a para Lacan, em suas articulações na cadeia significante (cf. Lacan, 1998). Trata-se, em todas essas aproximações, da referência àquilo que flutua - desliza - desloca - escapa; o imponderável (o que não cessa, a casa vazia, o insensato, o inconsciente).

Nessas teorias, o que muda é a própria noção de sujeito e a concepção da relação observador/observado, tão bem expressa por Claude Lévi-Strauss (1908) em sua introdução à obra de Marcel Mauss (cf. Lévi-Strauss, 1974). Se pensarmos tais noções em relação à ciência, saberemos inegavelmente que o observador interfere no objeto observado e - mais do que isso - o constrói e recria, sendo a ele impossível um grau máximo de neutralidade; tal interferência exclui, também dos objetos, a possibilidade de relações deterministas ou reducionistas.

Se alguma certeza pode restar de todas essas aberturas é justamente esta: na construção do conhecimento científico, assim 
como nas relações humanas (relações por excelência simbólicas), há sempre a presença do imprevisível, o que nos leva a recordar um dos aforismos mais conhecidos de Heráclito (535-475) - quem não espera o inesperado, nunca o encontrará ${ }^{11}$.

Voltemos ainda a Freud, agora pelas mãos de Lacan no $\mathrm{Se}$ minário 2 (1954-1955), O eu na teoria de Freud e na técnica da psicanálise. Lacan inicia o oitavo capítulo do seminário com uma colocação perturbadora: a de que não haveria empirismo possível sem uma conceituação avançada, permanentemente retomada e enriquecida. É dessa forma que inicia sua aproximação à Freud, tratando do que poderíamos chamar de questões de método. Julgamos pertinente reproduzir aqui as observações de Freud sobre a elaboração científica na obra As pulsões ${ }^{12}$ e suas vicissitudes, mesmo texto no qual Lacan baseia seu seminário, uma verdadeira lição sobre o processo de pesquisa e do desenrolar das teorias:

Ouvimos com freqüência a afirmação de que as ciências devem ser estruturadas em conceitos básicos claros e bem definidos. De fato, nenhuma ciência, nem mesmo a mais exata, começa com tais definições. $O$ verdadeiro início da atividade científica consiste antes na descrição dos fenômenos, passando então a seu agrupamento, sua classificação e sua correlação. Mesmo na fase de descrição não é possível evitar que se apliquem certas idéias abstratas ao material manipulado, idéias provenientes daqui e dali. (...) Só depois de uma investigação mais completa do campo de observação, somos capazes de formular seus conceitos científicos básicos com exatidão progressivamente maior, modificando-os de forma a se tornarem úteis e coerentes numa vasta área. Então,

11. Nas palavras do filósofo grego: Se não esperar o inesperado não se descobrirá, sendo indescobrivel e inacessivel (Os pensadores. Pré-socráticos. $4^{\prime \prime}$ ed. Volume I. São Paulo: Nova Cultural, 1989, p. 53, fragmento 180).

12. O texto em português foi traduzido para "Os instintos e suas vicissitudes". Adotamos aqui a palavra pulsões a partir do original em alemão por acreditarmos que ela expressa melhor o conceito freudiano (triebe), que não se referia a instintos em seus estudos. Note-se que a tradução brasileira segue a americana nessa terminologia específica. 
na realidade, talvez tenha chegado o momento de confiná-los em definições. $O$ avanço do conhecimento, contudo, não tolera qualquer rigidez, inclusive em se tratando de definições. $A$ física proporciona excelente ilustração da forma pela qual mesmo conceitos básicos, que tenham sido estabelecidos sob a forma de definições, estão sendo constantemente alterados em seu conteúdo. (Freud, 1997, p. 1)

A longa citação de Freud nos faz retomar a exposição a partir da filosofia da ciência e das concepções de método científico apresentadas anteriormente, pois remete ao processo de descoberta e de sistematização daquilo que foi encontrado em seus múltiplos movimentos de ir e vir. Trata-se, portanto, de um posicionamento em termos metodológicos a partir das instabilidades lançadas pela ciência, numa severa crítica à tentativa de estabelecer relações causais reducionistas ou, no caso da psicologia e da psiquiatria, de banalizar o humano a partir de uma biologização de seus comportamentos (aí estaríamos de fato no nível dos instintos).

São de Lacan as palavras que nos autorizam a estabelecer tais relações:

Lembrem-se do seguinte a respeito da exterioridade e da interioridade - esta distinção não tem nenhum sentido no nivel do real. O real é sem fissura. $O$ que lhes ensino, e aí Freud converge com o que podemos chamar de filosofia da ciência, é que este real, para apreendê-lo, não temos outros meios em todos os planos, e não somente no do conhecimento - a não ser por intermédio do simbólico. (Lacan, 1985, p. 129)

Freud introduz, a posteriori, na cena das ciências humanas, a incompletude e o caos, a noção de que uma teoria é sempre construída a partir de determinações específicas. A teoria psicanalítica elaborada a partir do inconsciente freudiano e de sua retomada por Lacan rompe com aquilo que estava anteriormente estabelecido por instaurar, onde antes havia certeza e unicidade, a falta e a divisão: 
Car la théorie du sujet entend rompre a avec les traditions philosophiques qui nous identifient à notre capacité de découvrir la réalité ou d'y trouver place. La "fin" de la psychanalyse n'est pas de nous apprendre à mesurer nos besoins à cette réalité. Elle est de nous affrontes au réel de notre existence, à l'infigurable de notre passé ou de notre désir, à tout ce qui nous divise, nous sépare de nos semblables et nous ouvre à une interprétation singulière. L'analyse ne se définit pas par la satisfaction d'un besoin dont nous pourrions connaître les fins, mais par la vérité d'un désir dont nous ne voulons rien savoir. (Rajchman, 1986, p. 10)

Freud coloca em jogo o irrepresentável e o inapreensível, aquilo que não pode ser articulado e que, por isso, ultrapassa o conceito de um sujeito racional orientado, centrado, direcionado a uma finalidade. Opera-se, em Freud, um descentramento do sujeito ${ }^{13}$ e, com isso, qualquer noção de essencialidade - seja ela divina ou racional - que assegurasse ao humano um papel e um lugar no universo é também deslocada.

Lacan avança nesse descentramento do sujeito:

13. De acordo com Hall, podemos definir o descentramento do sujeito (ou seu deslocamento) a partir de cinco grandes rupturas teóricas: 1) a redescoberta das idéias de Marx, na década de 60 , deslocando as proposições básicas da filosofia moderna em relação ao homem; 2) a descoberta do inconsciente por Freud, que ao apontar os mecanismos simbólicos a partir dos quais o inconsciente opera desmonta a lógica racional do sujeito congnoscente e instaura uma outra lógica em relação à construção da subjetividade; 3) as teorias lingüísticas de Saussure ao afirmar que nós não somos os autores daquilo que falamos, já que nos posicionamos a partir do interior de uma língua (sistema social) que nos precede e que determina nossa fala (ato individual) por meio de regras de funcionamento e sistemas de significado; 4) os estudos de Foucault sobre os regimes disciplinares e de controle social do moderno poder administrativo e da especialização do saber, impondo vigilância e punição sobre os indivíduos e suas práticas cotidianas; 5) o impacto dos chamados novos movimentos sociais (feminismo, movimento estudantil, contracultura, movimentos antibelicistas, luta pelos direitos civis, movimentos revolucionários, entre outros), que questionaram as formas dadas de organização política, social e cultural. Embora as distinções apresentadas por Hall possam ser questionadas, poucos negariam os efeitos desestabilizadores gerados por tais rupturas, especialmente nas ciências humanas (Hall, 2001, pp. 34-46). 
Or, la théorie lacanienne exclut d'entrée de jeu tout principe d'un centre de nature à orienter le sujet vers le Bien, à lui offrir un idéal, ou à le soumettre à des lois divines ou rationnelles. Tout au plus n'admet-elle qu'une 'structure' que chacun ou chacune fera sienne, selon les contingences particulières de son histoire - structure d'un sujet divisé, d'un sujet décentré. (Rajchman, 1986, p. 12)

Estabelece-se, assim, uma diferença radical em relação às concepções teóricas anteriores, quer sejam filosóficas, sociológicas, históricas, comunicacionais ou psicológicas: não há a suposição de um centro em torno do qual o sujeito se articularia mas uma divisão constituinte do sujeito que o divide duplamente - em relação a ele mesmo e em relação aos outros. Sujeitos divididos e descentrados, não trazemos em nós a unidade essencial ou natural que nós faz homens, como queria Aristóteles; tampouco somos dotados de uma reflexão racional e livre que nos faria adotar um princípio único de ação, como em Kant. Com John Rajchman, podemos estabelecer uma referência à concepção filosófica presente na ciência moderna:

De par l'avènement de la science moderne, un univers infini d'atomes errants aurait supplanté l'univers clos et plein de sens des vieilles cosmologies. En cet univers moderne, l'homme ne saurait plus trouver son Bien; le monde cesse d'être édifiant. Les présupposés de de l'âme antique ne peuvent survivre à ce bouleversement. Dans la mathématisation de la nature, l'âme antique est effectivement remplacée par le sujet moderne qui doit désormais se représenter un monde extérieur où il manque ses fins essentielles. (Rajchman, 1986, p. 15)

Descartes é quem começa por articular essa concepção da ciência moderna à filosofia (o próprio Lacan indica que sem Descartes não teria sido possível chegar ao conceito de inconsciente), correlação que estará na base da psicanálise lacaniana e de sua teoria do sujeito. De acordo com Rajchman, nessa nova articulação é a 
própria questão ética que deve ser revista: não se trata mais de uma ética baseada em uma finalidade em relação ao cosmos mas na relação do sujeito a sua própria representação. Por não mais considerar o saber como revelação divina, a modernidade separa dele também a verdade; a psicanálise radicaliza essa divisão ao afirmar que a verdade excede até mesmo o cogito cartesiano. Dividido em sua constituição, o sujeito não é mais sujeito da razão e não poderá jamais dizer toda a verdade. $\mathrm{O}$ inconsciente instaura-se como o termo articulador, podendo ser definido como aquilo que,

du désir, reste irreprésentable ou irréductible à quelque finalité souhaitable. (...) L'inconscient représente un autre discours, lequel implique en chacun une relation à soi, à son corps et à as langue, étranger à tout antique discours sur l'âme. (Rajchman, 1986, p. 17)

Nesse momento, uma outra pergunta nos interpela: a partir das contribuições de Lyotard e seu tecnologos, de uma certa concepção de ciência e do inconsciente freudiano, podemos ainda pensar em ciências humanas e, sobretudo, avançar até as chamadas ciências da linguagem? As reflexões de Dennis Hollier nos ajudarão a buscar os trilhos que podem nos conduzir nessa indagação. Consideramos oportuno compor nosso quadro conceitual com Hollier na introdução ao livro Panorama das ciências humanas (1973). Ao discutii as especificidades, alcances e limites das ciências ditas do homem, o autor apresenta uma interessante aproximação às ciências da linguagem, abrindo assim uma outra passagem.

Hollier começa o texto com um questionamento: o que reuniu os homens primeiro, falar ou trabalhar? A linguagem ou a necessidade? Como resposta, afirma apenas que tal anterioridade - ou a busca pelas origens - é impossível de ser estabelecida. Resta, então, investigar os possíveis caminhos de sua configuração.

Para buscar essas possibilidades, o autor estabelece a distinção entre ciências humanas e ciências exatas apontando que elas não se utilizam dos mesmos métodos; mas significaria isso que em alguma delas - nas ciências humanas - haveria menos rigor? A 
resposta a essa pergunta é negativa, já que as ciências humanas não podem ser tratadas como simples literatura, embora também não gozem do rigor atribuído às ciências exatas. Ao contrário das ciências da natureza, que separam a ciência do meio social, as ciências humanas repõem a ciência na história:

Se não há dúvidas de que as ciências humanas não correspondem ao que entendemos ainda recentemente por ciência, elas não são também "literatura", ao menos no sentido em que alguns as concebem. Uma ciência se define, inicialmente, por uma problemática própria e um campo especifico que explora. Sem dúvida, isto não exclui que ela passe por crises, que ela seja conduzida a reorganizações mais ou menos profundas (...). (Hollier, 1973, p. 2)

Se considerarmos que uma ciência se define apenas pelos problemas com os quais trabalha, seu objeto e seu campo específico, poderíamos concluir que as ciências humanas não são ciências. Nesse sentido, uma distinção fundamental é estabelecida por Hollier entre os dois domínios da ciência: nas ciências humanas, o interesse por outros domínios não é mera curiosidade, mas instaura a possibilidade de com eles também operar, trazê-los para seu campo, incluílos. Ao contrário das ciências exatas, as chamadas ciências humanas constituem discursos abertos, que não se definem a partir de si próprios, cruzando-se de um domínio para outro. Dessa forma, não haveria um único ideal de ciência; há vários campos convivendo. $\mathrm{O}$ próprio plural em ciências humanas indica que elas renunciaram à busca da unidade, à busca de $a$ ciência.

O que estaria em jogo, portanto, na expressão ciências humanas não é o humano, mas a própria ciência. Ao questionarem a dicotomia simplista das oposições entre alma e corpo, espírito e matéria, ordem simbólica e ordem produtiva, as ciências humanas abrem uma brecha para a pergunta: se estes termos fossem considerados equivalentes, precisamente quais deles caracterizariam o humano? A partir da abertura do conceito de ciência possibilitada por essa ruptura, Hollier aponta para um duplo deslocamento: de um 
lado, não se pode mais identificar a ciência apenas à mathesis; de outro, coloca a impossibilidade de conceber uma ciência livre de toda ideologia.

Roland Barthes já afirmara que os grupos sociais são constituídos pelos discursos que os falam e procurou demonstrar, em vários de seus trabalhos (como os livros Mitologias, $O$ sistema da moda) como as realidades discursivas organizam as sociedades. A realidade social seria, assim, o entrelaçamento de vários discursos. Isso não quer dizer que a linguagem deva se voltar sobre si mesma para tornar-se metalinguagem. Nesse sentido, é interessante o questionamento que Hollier apresenta de tal conceito. Ao ser definida como uma dobra sobre a linguagem para o estabelecimento de conceitos destinados a explicar a própria estrutura da linguagem, a metalinguagem incorre em uma tautologia e possibilita perguntarmonos: mas que linguagem dará conta da metalinguagem?

Um passo é dado nesse momento. Para além das ciências humanas, que questionam sobre si mesmas e sobre seus próprios conceitos, não podemos negligenciar as ciências da linguagem, possibilidade e razão deste mesmo questionamento. Portanto, ao indagarem sobre a ordem simbólica - ou a ordem dos significantes - as ciências da linguagem podem fornecer uma chave (cf. Kristeva, 1974) para a compreensão das estruturas sociais.

Referindo-se às teorias da linguagem, Hollier cita Monod ao afirmar que é a linguagem que teria criado o homem, antes que o homem a linguagem. (Hollier, 1973, p. 5) Vivemos, assim, no mundo dos significantes: o mundo nos chega pela linguagem. Aqui se estabelece outra importante ruptura: a idéia de que um texto deve ser relacionado a seu contexto é problematizada mais uma vez com a afirmação de que a própria linguagem já é o contexto, pois o mundo em que vivemos - assim como nós mesmos - só é na linguagem.

Isso pode ser percebido na relação do humano com a linguagem. Ao começar a falar, a criança passa do mundo das coisas para o mundo da linguagem, em um processo de substituição semelhante àquele que se opera na metáfora; desde seu nascimento, quando antes mesmo de falar já é falada por outros, recebendo um nome, a criança é inserida na ordem simbólica da linguagem e nas regras de 
organização e convivência da sociedade humana. Lévi-Strauss já alertara para o fato de que a linguagem não pôde nascer senão de uma só vez:

As coisas não se puderam pôr a significar progressivamente. Na seqüência de uma transformação cujo estudo não depende das ciências sociais, mas da biologia e da psicologia, efetuouse uma passagem de um estado em que nada tinha sentido a um outro em que tudo o possuía. (Lévi-Strauss, 1974, p. 41)

Dessa forma, podemos afirmar com Hollier que o homem é homem porque fala: só somos - humanos - porque falamos. $\mathrm{O}$ homem é, assim, determinado pela linguagem. Hollier aproxima-se de Kristeva:

A linguagem goza dessa situação privilegiada porque ela não pode ser um objeto, mas é através dela que as relações do sujeito e do objeto, que originaram a ciência, são denunciadas. A objetividade como exterioridade de um objeto e de um sujeito não é mais possível: ao invés de a linguagem vir a se tornar o objeto de um sujeito, é o sujeito que jamais será senão o sujeito do verbo: ocupado pela linguagem, a si destina um lugar em função de uma sintaxe que ele não controla. $O$ sujeito é, desde então, o lugar onde se manifestam os efeitos de ordens que lhe escapam. (Hollier; 1973, p. 6)

Das possibilidades abertas pelas descontinuidades introduzidas no campo das ciências chegamos ao inconsciente freudiano e, com ele, à possibilidade de pensarmos nas ciências humanas como ciências da linguagem. A ciência, como o próprio saber, não são absolutos. Trazem em si brechas e incertezas, pedaços e fendas que carregam um algo ainda por fazer. Ao se trilhar um percurso, haverá sempre um novo caminho esperando para ser percorrido, à semelhança das estruturas triádicas da semiótica peirceana que sempre abrem para algo mais, remetendo a um terceiro lugar, a uma nova possibilidade. 
Trata-se, portanto, da idéia tomada de empréstimo de cientistas e filósofos da ciência para afirmarmos a multiplicidade de teorias e de formas de concebê-las, fazendo com que diferentes aproximações coexistam de forma dinâmica e muitas vezes conflituosa. A questão da verdade - verdade do discurso -, assim como a questão da realidade, se pensadas a partir da linguagem e de uma determinada concepção de ciência, são concebidas como um constructo, como uma construção - assim como a própria ciência apresenta-se como uma construção na linguagem.

Se pudéssemos traçar, como recurso didático, um percurso pela história da lógica em sua tentativa de enunciar o mundo como totalidade - e, portanto, um percurso pelas relações entre linguagem e mundo -, estabeleceríamos a seguinte tríade de perguntas: 1) $O$ que vemos tão claramente em um raciocínio corresponde à verdade? 2) O que vemos tão claramente em um raciocínio corresponde à realidade? 3) A verdade corresponde à realidade?

Como vimos, a lógica aristotélica e seus desdobramentos ao longo de mais de vinte séculos situam-se no universo de preocupações da primeira questão; a lógica simbólica e matemática, nas derivações da segunda questão. Kant coloca-se entre um e outro ponto, abrindo a possibilidade para o terceiro questionamento, preocupação essencial da ciência. Pela via do discurso científico, assim como por aquela aberta na trilha de Freud, podemos concluir que não há correspondência possível entre as palavras, as idéias e as coisas, entre o mundo, o pensamento e a linguagem, mas esse real - o real da linguagem - é o único real que temos. Sua verdade - sempre meia verdade porque sempre incompleta - diz respeito à verdade da falta e da incerteza.

Sabemos que não há realidade fora da linguagem, mas essa realidade - ainda que precária, faltante - é a única a que temos acesso. Os teoremas da incompletude da ciência remetem a uma lógica das incertezas, a um discurso que abre sempre para uma outra possibilidade.

A partir dessas observações, voltemos à questão da verdade. Se a relação verdade-realidade é problematizada, uma pergunta se apresenta a nós: como então agir a partir de princípios éticos? 
Acreditamos que a resposta a essa última questão - e, portanto, resposta que inaugura assim um outro desafio - encontra-se na incerteza e no inconsciente, nas oscilações e nos interstícios do sujeito, ou seja, naquilo que a ciência e a psicanálise deixaram como legado ao século 21 .

\section{Bibliografia}

BARTHES, R. 1988. O rumor da língua. São Paulo: Brasiliense. . 1992. Elementos de semiologia. 15 ed. São Paulo: Cultrix.

BAUDRILLARD, J. 1991. Simulacros e simulação. Lisboa: Relógio d'Água (col. Antropos).

BENVENISTE, E. 1989. Problemas de lingüística geral I e II. Campinas: Pontes.

BORGES, J. L. 1961. "Del rigor en la ciencia”. In: El hacedor. Buenos Aires, Emecé, $2^{\mathrm{a}}$ reimp.

CORRÊA, I. 2001. A psicanálise e seus paradoxos. Seminários clínicos. Salvador/Recife: Ágalma/Centro de Estudos Freudianos do Recife.

FEYERABEND, P. 1979. "Consolando o especialista". In: Lakatos, I. \& MUSGRAVE, A. (orgs.). A crítica e o desenvolvimento do conhecimento. São Paulo: Cultrix/Edusp, pp. 244-284.

2000. Against method. $3^{\text {rd }}$ ed. New York/London: Verso.

FREITAS, J. M. M. 1992a. Comunicação e psicanálise. São Paulo: Escuta (col. ensaio).

. 1992b. Bemaldivida. São Paulo: Edusp (col. campi).

FREUD, S. 1974. "O mal estar na civilização". In: Obras psicológicas completas de Sigmund Freud. Vol. XXI, Rio de Janeiro: Imago.

1975. "Jokes and the unconscious". In: Standard Edition, London: Hogarth Press.

1997. "O instinto e suas vicissitudes". In: Edição Eletrônica Brasileira das Obras Psicológicas Completas de Sigmund Freud. Vol. XIV. Rio de Janeiro: Imago. 
. 1997. "O estranho". In: Edição Eletrônica Brasileira das Obras Psicológicas Completas de Sigmund Freud. Vol. XVII. Rio de Janeiro: Imago.

GADAMER, H. G. 1998. Verdade e método. $2^{2}$ ed. Petrópolis: Vozes (col. Pensamento Humano).

GIANNOTTI, J. A. 1995. Apresentação do mundo. Considerações sobre o pensamento de Ludwig Wittgenstein. São Paulo: Companhia das Letras.

GLEISER, M. 2000. "Um pouco de caos é sempre bom". Folha de S. Paulo, caderno mais!, 11/06, p. 29.

HALL, S. 2001. A identidade cultural na pós-modernidade. 5` ed. Rio de Janeiro: DP\&A.

HOLLIER, D. (org.). 1973. Panorama des sciences humaines. "Introdução" (tradução). Paris: NRF (col. Le Point du Jour).

JAKOBSON, R. 1965. Essais de linguistique générale. Paris: Minuit.

KOYRÉ, A. 1982. Estudos de história do pensamento científico. São Paulo: Forense/UnB.

KRISTEVA, J. 1974. História da linguagem. Lisboa: Edições 70 (col. Signos).

KUHN, T. S. A estrutura das revoluções científicas. São Paulo: Perspectiva, 1975.

LACAN, J. 1985. "O eu na teoria de Freud e na técnica da psicanálise". O Seminário. Livro 2. Rio de Janeiro: Jorge Zahar.

. 1990. "Os quatro conceitos fundamentais da psicanálise". O Seminário. Livro 11. 4" ed. Rio de Janeiro: Jorge Zahar.

1998. Escritos. Rio de Janeiro: Jorge Zahar (col. Campo Freudiano no Brasil).

LEMAIRE, A. 1989. “Os dois grandes eixos da linguagem”. Jacques Lacan, uma introdução. 4 "ed. Rio de Janeiro: Campos.

LÉVI-STRAUSS, C. 1967. "Introdução à obra de Marcel Mauss". In: Estruturalismo. Antologia de textos teóricos. São Paulo/Lisboa: Martins Fontes/Portugália (col. Direcções).

LYOTARD, J.-F. 1990. O inumano: considerações sobre o tempo. Lisboa: Estampa, (col. Margens). 
MANDELBROT, B. 1993. "Fractais: uma forma de arte a bem da ciência". In: PARENTE, A.(org.). Imagem-máquina. São Paulo: 34, pp. 195-200.

MANNONI, M. 1979. La théorie comme fiction. Freud, Groddeck, Winnicott, Lacan. Paris: Seuil.

PEIRCE, C. S. 1977. Semiótica. São Paulo: Perspectiva (col. Estudos).

POPPER, K. 1982. Conjecturas e refutações. Brasília: UnB.

QUÉRÉ, L. 1982. Des miroirs équivoques. Paris: A.-M..

RAJCHMAN, J. 1986. Le savoir-faire avec l'inconscient. Ethique et psychanalyse. New York: William Blake \& Co..

ROCHA, R. L. M. 1998. "Saber crítico e rupturas metodológicas: comunicação e pluralidade". Anais. XXI Congresso Brasileiro de Ciências da Comunicação (Intercom). Recife: Universidade Federal de Pernambuco (Recife), setembro.

RUELLE, D. 1993. Acaso e caos. $2^{2}$ ed. São Paulo: Editora da Unesp (col. Biblioteca Básica).

THOM, R. 1985. Parábolas e catástrofes - entrevista sobre matemática, ciência e filosofia. Lisboa: Dom Quixote (col. Biblioteca de Filosofia Opus). 